\title{
Outcomes of Transsphenoidal Surgery in Growth Hormone-Secreting Pituitary Adenomas
}

\author{
Oleksandr Voznyak ${ }^{1}$ Andrii Lytvynenko ${ }^{1}$ Oleg Maydannyk ${ }^{1} \quad$ Roman llyuk $^{1}$ Yaroslav \\ Zinkevych ${ }^{1}$ Nazarii Hryniv²
}

${ }^{1}$ Centre of Neurosurgery, Clinical Hospital "Feofaniya," Kyiv, Ukraine ${ }^{2}$ Department of Neurosurgery, Shupyk National Medical Academy of Postgraduate Education, Kyiv, Ukraine
Address for correspondence Oleksandr Voznyak, MD, PhD, Centre of Neurosurgery, Clinical Hospital "Feofaniya," Zabolotny Street, 21, Kyiv, Ukraine 03143 (e-mail: drvoznyak@gmail.com).

Indian J Neurosurg 2021;1:61-64.

\begin{abstract}
Keywords

- pituitary adenoma

- acromegaly

- transsphenoidal approach

Growth hormone $(\mathrm{GH})$-secreting pituitary adenomas (PA) make up 15 to $20 \%$ of total amount of hormonally active adenomas. In addition to acromegaly and gigantism, these tumors cause deep metabolic disturbances. Its systemic impact leads to increased mortality ratio of 1.32 compared with general population. Surgical removal remains the priority treatment option in controlling acromegaly and provides endocrinologic remission in up to $72 \%$ patients. A total of 92 patients were included in the study. All surgeries were performed via microscopic transsphenoidal approach (TSA) by the senior author in our institution between December 2009 and October 2019. Only patients who were followed-up with $75 \mathrm{~g}$ oral glucose tolerance tests (OGTTs), $\mathrm{GH}$, and insulin-like growth factor I (IFG-I) measurements preoperatively, 1 week, and every 6 months postoperatively were analyzed. Based on standard preoperative 1.5-T MR imaging with contrast enhancement, the adenomas were identified and distributed according to the size and KNOSP classification. The efficacy depends on KNOSP grade, which is directly correlated with invasiveness to cavernous sinus (CS). Grades 3 and 4 are unfavorable factors influencing prognosis. Excluding grade 0 adenomas, as the surgery was not difficult with the excellent outcomes, we reached $75 \%$ (36 out of 48 ) remission in grade 1 to 2 groups. In contrast, only 17\% (2 out of 12) had successful outcomes after surgery alone. In conclusion, the study demonstrates the efficiency of TS surgery in patients with confirmed $\mathrm{GH}$-secreting PA.
\end{abstract}

\section{Introduction}

Growth hormone (GH)-secreting pituitary adenomas (PA) make up 15 to $20 \%$ of total amount of hormonally active adenomas. ${ }^{1}$ They can purely secret $\mathrm{GH}$ or cosecrete prolactin (PRL) in up to $40 \%{ }^{2,3}$ In addition to acromegaly and gigantism, these tumors cause deep metabolic disturbances. Its systemic impact leads to increased mortality ratio of 1.32 compared with the general population. ${ }^{4}$ It is worth mentioning the fact that the high level of insulin-like growth factor-1 (IGF-1) in acromegaly is related to an increased risk of some cancers. ${ }^{5,6}$ The mean diagnostic delay is 7 years due to insidious symptoms. ${ }^{7}$

DoI https://doi.org/ $10.1055 / \mathrm{s}-0041-1726134$ ISSN 2277-954X.
Surgical removal remains the priority treatment option in controlling acromegaly and provides endocrinologic remission in up to $72 \%$ patients. ${ }^{1,8}$ Size has an inverse relationship with success rate: $87 \%$ for micro- and $66 \%$ for macroadenomas. ${ }^{9}$ Cavernous sinus (CS) invasion seems to be the most important factor for remission. ${ }^{10,11}$ Medical and radiation therapy provide remission rates ranging from $42 \%$ to $60 \%$, but takes more time for results, and have long-term multisystem comorbidities. ${ }^{29,10}$ Conservative approach may be used if the patient is not a surgery candidate or when the resection fails to provide biochemical remission. Continuous administration of drugs has a higher cost, and its withdrawal leads to relapse

(C) 2021. Neurological Surgeons' Society of India.

This is an open access article published by Thieme under the terms of the Creative Commons Attribution-NonDerivative-NonCommercial-License, permitting copying and reproduction so long as the original work is given appropriate credit. Contents may not be used for commercial purposes, or adapted, remixed, transformed or built upon. (https://creativecommons.org/licenses/by-nc-nd/4.0/).

Thieme Medical and Scientific Publishers Pvt. Ltd. A-12, 2nd Floor, Sector 2, Noida-201301 UP, India 
of symptoms. ${ }^{12}$ Radiation therapy takes 2 to 3 years to reach the effect and can lead to hypopituitarism in $85 \%$ of patients. ${ }^{13,14}$

The lack of data related to prognostic parameters for patients with acromegaly attracts attention to this issue. Thus, the aim of this study was to demonstrate the results of $\mathrm{GH}$-secreting PA surgical treatment that might assist in strategy decisions and subsequently better outcomes.

\section{Methods}

\section{Patient Population}

By analyzing the medical records, males and females, aged $>18$ years, with histologically and clinically verified GH-secreting PA were retrospectively included in the study. All surgeries were performed via microscopic transsphenoidal approach (TSA) with endoscopic assistance by the senior author in our institution between December 2009 and October 2019. Only patients who were followed-up with $75 \mathrm{~g}$ oral glucose tolerance tests (OGTTs), GH, and IFG-I measurements preoperatively, 1 week, and every 6 months postoperatively were analyzed. In addition, all patients underwent a complete clinical, neurological, and ophthalmological examination. The diagnosis was established based on the results of clinical picture, laboratory parameters, and MRI data. Consent was obtained by all participants in this study. Expert Commission of the Clinical Hospital "Feofaniya" of the State Administration of Affairs issued approval Quality Management System Certificate UA126Q01 1907601.

\section{Radiologic Evaluation}

Based on standard preoperative 1.5-T MR imaging with contrast enhancement, the adenomas were identified and distributed according to the size and KNOSP classification. Tumors with the maximal diameter of greater than or equal to $10 \mathrm{~mm}$ were defined as macroadenomas, while microadenomas were those with maximal diameter of less than $10 \mathrm{~mm}$. According to KNOSP classification, grades were distinguished from each other by a medial tangent, the intercarotid line (through the cross-sectional centers), and a lateral tangent on the intra- and supracavernous internal carotid arteries. Grade
0 represented the tumor medial to medial tangent and grade 4 corresponded to the total encasement of the intracavernous carotid artery. ${ }^{15,16}$ We excluded adenomas with suprasellar and antesellar nodes, isolated expansion beyond the medial line and tumor-induced hydrocephaly, as these cases required either transcranial approach or complex several-staged treatment.

Postoperative MRI was performed within 3 months and 1 year after surgery to evaluate the extent of resection. ${ }^{17}$ Gross total resection (GTR) was defined as complete tumor removal confirmed by the surgeon intraoperatively and no evidence of residual tumor on postoperative MRI within 3 months and a year after the procedure. Subtotal resection (STR) was defined as the presence of residual tumor left by the surgeon intraoperatively or proven on images.

\section{Endocrinologic Evaluation}

Elevated IGF-1 confirmed a diagnosis of acromegaly. In cases of equivocal IGF-1 levels, an OGTT was performed, and lack of GH suppression to $<1 \mu \mathrm{g} / \mathrm{L}$ was diagnostic. ${ }^{18}$ Efficacy of surgery defines disease control by mean fasting random serum $\mathrm{GH}$ level $<2.5 \mu \mathrm{g} / \mathrm{L}$ or normalization of age- and gender-matched IGF-1 after the procedure.

All patients underwent combined pituitary function tests before surgery to estimate anterior pituitary.

\section{Statistical Analysis}

Statistical analyses were conducted using SPSS statistics version 23 . The quantitative data was tested for normality. The mean of numeric variable between the two groups were compared with independent-samples two-tailed $t$-tests. The distributions of categorical variables between the two groups were compared using Chi-squared test.

\section{Results}

A total of 92 patients were included in the study. The median duration of symptoms until the treatment was 4 years. Acral enlargement (86\%) and macroglossia (31\%) were the prominent features. Carpal tunnel syndrome and arterial hypertension were associated in $18 \%$ and $61 \%$, respectively. Patients'

Table 1 Clinical characteristics and surgical outcomes of $\mathrm{GH}$-secreting pituitary adenomas

\begin{tabular}{|c|c|c|c|c|c|c|c|c|c|c|}
\hline & \multicolumn{10}{|c|}{ KNOSP classification } \\
\hline & \multicolumn{2}{|c|}{ Grade 0} & \multicolumn{2}{|c|}{ Grade 1} & \multicolumn{2}{|c|}{ Grade 2} & \multicolumn{2}{|c|}{ Grade 3} & \multicolumn{2}{|r|}{ Grade 4} \\
\hline Number of patients & \multicolumn{2}{|l|}{$33(36 \%)$} & \multicolumn{2}{|c|}{27 (29\%) } & \multicolumn{2}{|c|}{$21(23 \%)$} & \multicolumn{2}{|l|}{$7(8 \%)$} & \multicolumn{2}{|c|}{$5(4 \%)$} \\
\hline $\begin{array}{l}\text { Median GH level at } \\
\text { diagnosis in ng/mL }\end{array}$ & \multicolumn{2}{|l|}{26.4} & \multicolumn{2}{|l|}{25.3} & \multicolumn{2}{|l|}{27.9} & \multicolumn{2}{|l|}{31.6} & \multicolumn{2}{|l|}{30.5} \\
\hline $\begin{array}{l}\text { Median IGF-1 level at } \\
\text { diagnosis in } \mathrm{ng} / \mathrm{mL}\end{array}$ & \multicolumn{2}{|l|}{553.5} & \multicolumn{2}{|l|}{646.5} & \multicolumn{2}{|l|}{752.7} & \multicolumn{2}{|l|}{569.4} & \multicolumn{2}{|l|}{617} \\
\hline Microadenoma & \multicolumn{2}{|l|}{32 (97\%) } & \multicolumn{2}{|l|}{$2(7 \%)$} & \multicolumn{2}{|l|}{0} & \multicolumn{2}{|l|}{0} & \multicolumn{2}{|l|}{0} \\
\hline Macroadenoma & \multicolumn{2}{|l|}{$1(3 \%)$} & \multicolumn{2}{|c|}{$25(93 \%)$} & \multicolumn{2}{|c|}{$21(100 \%)$} & \multicolumn{2}{|c|}{$7(100 \%)$} & \multicolumn{2}{|c|}{$5(100 \%)$} \\
\hline Remission & \multicolumn{2}{|c|}{$33(100 \%)$} & \multicolumn{2}{|c|}{$23(85 \%)$} & \multicolumn{2}{|c|}{$13(62 \%)$} & \multicolumn{2}{|l|}{$2(28 \%)$} & \multicolumn{2}{|l|}{0} \\
\hline $\begin{array}{l}\text { Radicality of } \\
\text { resection }\end{array}$ & $\begin{array}{l}\text { GTR } \\
33 \\
(100 \%)\end{array}$ & $\begin{array}{l}\text { STR } \\
0\end{array}$ & $\begin{array}{l}\text { GTR } \\
24 \\
(89 \%)\end{array}$ & $\begin{array}{l}\text { STR } \\
3 \text { (11\%) }\end{array}$ & $\begin{array}{l}\text { GTR } \\
13 \\
(62 \%)\end{array}$ & $\begin{array}{l}\text { STR } \\
8 \text { (38\%) }\end{array}$ & $\begin{array}{l}\text { GTR } \\
3(43 \%)\end{array}$ & $\begin{array}{l}\text { STR } \\
4(57 \%)\end{array}$ & $\begin{array}{l}\text { GTR } \\
0\end{array}$ & $\begin{array}{l}\text { STR } \\
5(100 \%)\end{array}$ \\
\hline
\end{tabular}

Abbreviations: GH, growth hormone; GTR, gross total resection; IGF-1, insulin-like growth factor 1; STR, subtotal resection. 
main characteristics and distribution are shown in - Table $\mathbf{1 .}$ The mean tumor volume was $4.8 \mathrm{~cm}^{3}$ and the most common KNOSP grade was 0 (36\%). Grade 1 and 2 groups consisted of approximately identical number of patients. Less common were grade 3 and 4 with $8 \%$ and $4 \%$, respectively. Microadenomas consisted $97 \%$ of grade 0 tumors. In contrast, grade 1 included only $7 \%$ of adenomas less than $1 \mathrm{~cm}$ in diameter. From grade 2 to grade 4, all tumors were macro. The GTR as well as remission were reached in $100 \%$ in the first group. In 24 out of 27 patients with KNOSP grade 1, the GTR and remission were achieved in all but one case. Surgery was $100 \%$ effective in grade 3 group. A minority of procedures were successful in grade 3 adenomas (3 out of 7). Neither operation led to acromegaly control in KNOSP group 4. Mean follow-up time was 19 months ( $p=0.125)$ after surgery. Patients without GTR and biochemical remission were sent for radiotherapy. If the remission was not reached in 3 months, further tactics were defined by endocrinologist. Cerebrospinal fluid (CSF) rhinorrhea in four patients was resolved after surgical repair. Ten patients had transient diabetes insipidus. We had no other complications. Median GH level at diagnosis was $28.3 \mathrm{ng} / \mathrm{mL}(p=0.134)$; median IGF-1 level at diagnosis was $627 \mathrm{ng} / \mathrm{mL}(p=0.276)$; median patients age was 42 years ( $p=0.238)$.

\section{Discussion}

According to previous investigations, the overall remission after TS surgery is 42 to $72 \%$. Surgical removal remains the first-line treatment. ${ }^{6,7,19}$ The efficacy depends on KNOSP grade, which is directly correlated with invasiveness to CS. Grades 3 and 4 are unfavorable factors influencing prognosis. ${ }^{20}$ Excluding grade 0 adenomas, as the surgery was not difficult with the excellent outcomes, we reached 75\% (36 out of 48 ) remission in grade 1 to 2 groups. In contrast, only $17 \%$ ( 2 out of 12 ) had successful outcomes after surgery alone. However, the population in these groups was relatively small. Some surgeons practice debulking TS surgery in combination with medications and radiosurgery. They believe that aggressive excision risks overlap the benefits. ${ }^{21-23}$ In contrast, our surgeries on adenomas with CS invasions were effective and without marked complications.

Surgical technique could be improved by precise analysis of MRI and understanding the intraoperative relations, especially infundibulum and normal hypophysis location. As the removal of invasive tumors is often associated with CSF leak, as a rule, we use patient's fat application, followed by anterior wall of sphenoid sinus reimplantation. Our study also confirms that postoperative IGF-1 is the predictor for uncontrolled disease. We found it crucial for definition of appropriate treatment strategy in complex with intraoperative findings and postoperative MRI. We had two cases where the resection was estimated as gross total, but hormonal levels were not satisfactory.

\section{Conclusion}

In conclusion, the study demonstrates the efficiency of TS surgery in patients with confirmed GH-secreting PA. The experienced surgeon and adequate preparation could provide the safe resection that leads to remission or, at least, minimization of adenoma's influence with subsequent improvement of the success of adjuvant therapy.

\section{Funding \\ None. \\ Conflict of Interest \\ None declared.}

\section{References}

1 Melmed S, Colao A, Barkan A, et al; Acromegaly Consensus Group. Guidelines for acromegaly management: an update. J Clin Endocrinol Metab 2009;94(5):1509-1517

2 Mehta GU, Lonser RR. Management of hormone-secreting pituitary adenomas. Neuro-oncol 2017;19(6):762-773

3 Georgia N, Niki K, Endocrinology: Adult and Pediatric. 7th ed. Philadelphia: Elsevier; 2016:188-208

4 Dekkers OM, Biermasz NR, Pereira AM, Romijn JA, Vandenbroucke JP. Mortality in acromegaly: a metaanalysis. J Clin Endocrinol Metab 2008;93(1):61-67

5 Abreu A, Tovar AP, Castellanos R, et al. Challenges in the diagnosis and management of acromegaly: a focus on comorbidities. Pituitary 2016;19(4):448-457

6 Hamurcu Z, Cakir I, Donmez-Altuntas H, et al. Micronucleus evaluation in mitogen-stimulated lymphocytes of patients with acromegaly. Metabolism 2011;60(11):1620-1626

7 Rajasoorya C, Holdaway IM, Wrightson P, Scott DJ, Ibbertson HK. Determinants of clinical outcome and survival in acromegaly. Clin Endocrinol (Oxf) 1994;41(1):95-102

8 Melmed S, Casanueva F, Cavagnini F, et al. Consensus statement: medical management of acromegaly. Eur J Endocrinol 2005;153(6):737-740

9 Starke RM, Raper DMS, Payne SC. Vance ML, Oldfield EH, Jane JA Jr. Endoscopic vs microsurgical transsphenoidal surgery for acromegaly: outcomes in a concurrent series of patients using modern criteria for remission. J Clin Endocrinol Metab 2013;98(8):3190-3198

10 Moon JH, Kim EH, Kim SH. Snare technique for the remodeling of the redundant arachnoid pouch to prevent cerebrospinal fluid rhinorrhea and hematoma collection during transsphenoidal surgery for suprasellar-extended pituitary tumors. J Neurosurg 2016;125(6):1443-1450

11 Kim EH, Roh TH, Park HH, Moon JH, Hong JB, Kim SH. Direct suture technique of normal gland edge on the incised dura margin to repair the intraoperative cerebrospinal fluid leakage from the arachnoid recess during transsphenoidal pituitary tumor surgery. Neurosurgery 2015;11(Suppl 2) :26-31, discussion 31

12 Castinetti F, Régis J, Dufour H, Brue T. Role of stereotactic radiosurgery in the management of pituitary adenomas. Nat Rev Endocrinol 2010;6(4):214-223

13 Lorenzo-Solar M, Castro A, Peino R, Fernandez-Alvarez J, Dieguez C, Casanueva FF. Can treatment with somatostatin analogs replace neurosurgery? J Endocrinol Invest 2005;28(11, Suppl International):48-52

14 van der Lely AJ, Biller BMK, Brue T, et al. Long-term safety of pegvisomant in patients with acromegaly: comprehensive review of 1288 subjects in ACROSTUDY. J Clin Endocrinol Metab 2012;97(5):1589-1597

15 Minniti G, Jaffrain-Rea M-L, Osti M, et al. The long-term efficacy of conventional radiotherapy in patients with GH-secreting pituitary adenomas. Clin Endocrinol (Oxf) 2005;62(2):210-216

16 Mitsumori M, Shrieve DC, Alexander E III, et al. Initial clinical results of LINAC-based stereotactic radiosurgery and 
64 Outcomes of Transsphenoidal Surgery in Growth Hormone-Secreting Pituitary Adenomas Voznyak et al.

stereotactic radiotherapy for pituitary adenomas. Int J Radiat Oncol Biol Phys 1998;42(3):573-580

17 Stofko DL, Nickles T, Sun H, Dehdashti AR. The value of immediate postoperative MR imaging following endoscopic endonasal pituitary surgery. Acta Neurochir (Wien) 2014;156(1):133-140

18 Katznelson L, Laws ER, Jr, Melmed S, et al; Endocrine Society. Acromegaly: an endocrine society clinical practice guideline. J Clin Endocrinol Metab 2014;99(11):3933-3951

19 Lonser RR, Kindzelski BA, Mehta GU. Jane JA Jr, Oldfield EH. Acromegaly without imaging evidence of pituitary adenoma. J Clin Endocrinol Metab 2010;95(9):4192-4196
20 Wilson $C B$, Neurosurgical management of large and invasive pituitary tumors. In: George TT, William FC, eds. Clinical Management of Pituitary Disorders. New York, NY: Raven Press; 1979:335-342

21 Hofstetter CP, Shin BJ, Mubita L, et al. Endoscopic endonasal transsphenoidal surgery for functional pituitary adenomas. Neurosurg Focus 2011;30(4):E10

22 Shin SS, Tormenti MJ, Paluzzi A, et al. Endoscopic endonasal approach for growth hormone secreting pituitary adenomas: outcomes in 53 patients using 2010 consensus criteria for remission. Pituitary 2013;16(4):435-444

23 Sherlock M, Woods C, Sheppard MC. Medical therapy in acromegaly. Nat Rev Endocrinol 2011;7(5):291-300 